\title{
Spatial variability of micro-climatic conditions within a mid-latitude deciduous forest
}

\author{
C. S. B. Grimmond*, S. M. Robeson, J. T. Schoof \\ A tmospheric Science Program, Department of Geography, Indiana University, Bloomington, Indiana 47405, USA
}

\begin{abstract}
Micro-climatic differences within forests exert important controls, notably on understory composition, wildlife habitat, and many biogeochemical processes. This study documents the spatial variability and temporal evolution of micro-climatic conditions (air temperature, relative humidity, solar radiation and wind speed) within a mid-latitude deciduous forest, over 3 growing seasons (1995 to 1997). For all sites, in all years, conditions change markedly at the start of the growing season (Days 120 to 145), simultaneous with onset of leaf-out and the development of full canopy cover. Below the fully developed canopy, radiation and wind speed are significantly reduced, both in magnitude and duration, while relative humidity increases. Within the forested ravines, spatial differences in daily maximum air temperature range from 0.5 to $4.1^{\circ} \mathrm{C}$ (average of $2^{\circ} \mathrm{C}$ ) and in minimum air temperatures from 0 to $4.5^{\circ} \mathrm{C}$ (average of $1^{\circ} \mathrm{C}$ ). Within the forest, solar radiation varies by $100 \mathrm{~W} \mathrm{~m}^{-2}$ (when maximum values are $<200 \mathrm{~W} \mathrm{~m}^{-2}$ ), minimum relative humidity varies by 10 to $15 \%$, and wind speed by $0.5 \mathrm{~m} \mathrm{~s}^{-1}$. Local weather conditions have a strong influence on the spatial and temporal variability of all the micro-climatic variables considered. In general, differences within the forest are greater on clear, sunny days. Once the canopy closes, the effects of topography and associated aspect/geometry dominate over micro-scale differences due to canopy structure. Less radiation, lower air temperatures, higher relative humidity, and higher wind speeds all are documented at the bottom of the ravines. The differences in micro-climatic conditions measured within the forest are of the same order as those measured in previous studies contrasting open and forest sites. Such spatial variability should be considered in studies of ecological and biogeochemical processes in secondary growth deciduous forests.
\end{abstract}

KEY WORDS: Micro-climate $\cdot$ Below-canopy $\cdot$ Mid-latitude deciduous forest

\section{INTRODUCTION}

It is well-documented that forest canopies create distinct understory micro-climates (see examples and explanations in Geiger 1965, Lee 1978, Oke 1987, McCaughey et al. 1997). Below the forest canopy, solar radiation is reduced, day-time air temperature, at least on sunny days, is decreased, humidity is enhanced, and wind speed is lowered and often effectively decoupled from regional flow (see, for example, the studies of Chen et al. 1993 and M orecroft et al. 1998). Such effects vary with distance from the forest edge, canopy structure, topography (which influences aspect and drainage), and soil type. These micro-climatic differ-

*E-mail: grimmon@indiana.edu ences are important in terms of the structure and function of the entire forest, and are primary influences on understory composition, wildlife habitat, and many biogeochemical processes. Increasing attention is being directed to such effects and also to the potential for greenhouse-induced climate change to alter belowcanopy conditions and thus to affect the ecology and biogeochemistry of forests (Rodenhouse 1992, Root \& Schneider 1993, Winnett 1998).

Although many studies of these effects, and predictions of their consequences, have been conducted, most rely on just a few sites and provide limited documentation of spatial variability of conditions within the forest. Commonly, paired comparisons are made, where an open 'control' site is contrasted with a site in a forest. Notable exceptions do exist, for example, the work of Chen \& Franklin (1997), who undertook 
measurements at multiple sites within a coniferous forest. However, data on the spatial variability of belowcanopy conditions for a range of forest types, which must be considered when evaluating potential climatic impacts, remain limited.

The objective of this study is to document the spatial variability of climatic conditions within a mid-latitude secondary growth deciduous forest and their temporal evolution over the growing season. In addition, the effects of specific weather conditions are considered. Of particular interest is air temperature, although information on relative humidity, radiative fluxes (incoming solar and net all-wave), and wind speed is also included. Growing season conditions are considered, both because of their inherent importance and because below-canopy and open-site conditions typically are very similar when trees are not 'in leaf' (see, for example, Morecroft et al. 1998 and references cited therein). A large number of measurement sites were used during 1 yr (1997), while additional data from a more restricted number of sites for multiple years (1995 to 1997) are included to provide insight into interannual variability. The results have broad implications for research on ecological and biogeochemical processes within secondary growth deciduous forests.

\section{FIELD-SITE DESCRIPTION}

Climatic data were collected during the growing seasons of 1995 to 1997 in the Pleasant Run Unit of Hoosier National Forest (HNF), south central Indiana (Fig. 1). HNF and surrounding state forests are part of an extensive area of deciduous forests in eastern N orth A merica (Braun 1972, Loveland et al. 1995). In addition, HNF represents one of the most continuously forested areas in the Midwestern US (Robinson et al. 1995). The study area (centered on $39^{\circ} 6^{\prime} \mathrm{N}, 86^{\circ} 21^{\prime} \mathrm{W}$ ) consists of 2 contiguous watersheds (ravines) composed of 97 ha of secondary growth deciduous forest. Within a $3 \mathrm{~km}$ radius of the center of the field sites, there is over $90 \%$ forest cover. The nearest agricultural activity is over $5 \mathrm{~km}$ to the north. As a result, the ravines currently have a low level of direct human disturbance.

Tree species in the area are diverse. Dominant canopy species are up to $100 \mathrm{yr}$ old and include sugar maple Acer saccharum, American beech Fagus grandifolia, tulip poplar Liriodendron tulipifera, white oak Quercus alba, chestnut oak Quercus cataneifola, and shagbark hickory Carya ovata. The understory shrubs and trees generally consist of flowering dogwood Cornus florida, maple-leaf viburnum Viburnum acerifolium, American beech, sassafras Sassafras albidum, pawpaw Asimina tribola, spicebush Linder benzoin, sugar maple, white ash Fraxinus americana, and slippery elm UImus rubra. The topography consists of relatively flat ridge-tops with deeply incised ravines; elevations range from 180 to $245 \mathrm{~m}$ (590 to $800 \mathrm{ft}$ ) above mean sea level. HNF lies just south of the limit of the Wisconsinan glaciation.

\section{DATA AND METHODS}

3.1. Field observations. Two sets of data are reported here. First, air temperature was measured at 21 sites in 2 ravines for the growing season of 1997 (Figs. $1 \& 2$ ). One ravine is oriented east-west (E-W ravine); the other is oriented south-north (S-N ravine) (Fig. 1). Both ravines have very similar morphometry (Fig. 2). Second, air temperature, humidity, incoming solar and net all-wave radiation, wind speed, soil heat flux and soil moisture were measured at 3 fixed sites within the $\mathrm{E}-\mathrm{W}$ ravine (Fig. 1) for the growing seasons 1995 to 1997 inclusive. One site was located at the bottom of ravine, one on the east side of the ravine, and the other on the west side (Fig. 1). The first set of data, air temperature for the summer of 1997, provides detailed information on the spatial variability of conditions within the forest. The second set provides a fuller suite of meteorological observations and insight into year-to-year variability in the below-canopy conditions.

Shielded HOBO sensors (manufactured by Onset, Pocasset, MA) were used for the study of spatial variability in 1997. Manufacturer's specifications on the $\mathrm{HOBO}$ sensors indicate a resolution of $-0.2^{\circ} \mathrm{C}$ and an accuracy of $\pm 0.7^{\circ} \mathrm{C}$. The sensors were placed along transects across the 2 ravines ( $\mathrm{E}-\mathrm{W}$ and $\mathrm{S}-\mathrm{N}$ ), on average approximately $30 \mathrm{~m}$ apart (Fig. 1). The sensors were mounted in the lower-most branches of trees at heights of approximately $2.5 \mathrm{~m}$. Data were sampled at $0.2 \mathrm{~Hz}$, and averaged over $30 \mathrm{~min}$.

For the more extensive micro-meteorological stations, deployed at the 3 sites during 1995 to 1997, temperature and relative humidity were measured with Vaisala/Campbell Scientific HMP35C sensors. These sensors have an accuracy of $\pm 0.2^{\circ} \mathrm{C}$ (resolution $<0.1^{\circ} \mathrm{C}$ ) for temperature and an accuracy of $\pm 2 \%$ for 0 to $90 \%$ and $\pm 3 \%$ for 90 to $100 \%$ (resolution $<0.1 \%$ ) relative humidity. Solar radiation was measured with LiCor LI-200S sensors (resolution $0.1 \mathrm{~W} \mathrm{~m}^{-2}$ ), and wind speed with RM Young 03001 wind sentry (threshold $0.2 \mathrm{~m} \mathrm{~s}^{-1}$; resolution $0.15 \mathrm{~m} \mathrm{~s}^{-1}$ ). The sensors were mounted on tripods approximately $1.5 \mathrm{~m}$ above the ground. Ambient conditions were sampled at $0.2 \mathrm{~Hz}$ and averages recorded over $30 \mathrm{~min}$. Data were recorded using Campbell Scientific (CSI) 21X dataloggers. All times referred to are Eastern Standard Time. 
Fig. 1. Location of field sites and topography within Hoosier $\mathrm{Na}$ tional Forest (HNF). Extent of HNF and Morgan Monroe State Forest (MMSF) shown in inset. Full stations: fixed micrometeorological equipment (measuring temperature, relative humidity, solar radiation and wind speed). Data from stations in the E-W ravine are presented in this paper. Hobo 1997: location of the temperature sensors (numbering sequence indicated) used in the intensive study of spatial variability

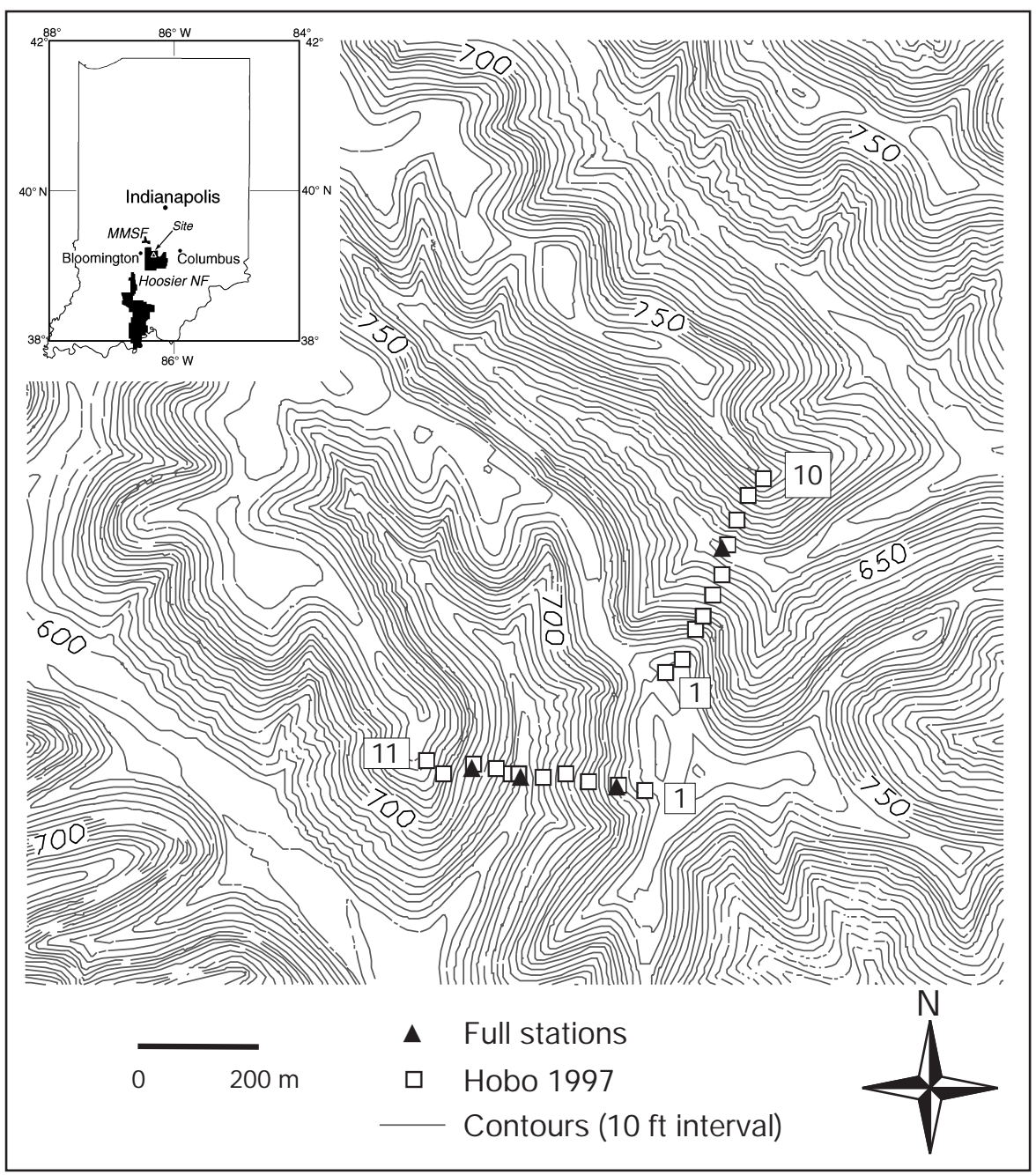

All sensors were inter-compared at the beginning and end of each field season. All data have been corrected for the inter-instrument differences. After correction, the temperature sensors during the calibration periods produced mean absolute differences that were typically much less than $0.2^{\circ} \mathrm{C}$. Thus, temperature differences in the forest are interpreted in terms of exposure and not due to instrumental error. However, it is important to note that the absolute data from the HOBO sensors and that from the fixed micro-meteorological stations are not directly comparable because of differences in the responses of the sensors and their mounting heights in the forest.

Sky view factors (SVF) were determined as a measure of the foliation and architecture of the forest canopy at each site. Hemispheric photographs were taken at approximately weekly intervals using a vertically mounted camera (Olympus OM -1) equipped with a Sigma F4 fisheye lens. The camera was mounted on a tripod at a height of $1 \mathrm{~m}$, leveled horizontally using a bubble level, and always oriented so that north corre- sponded to the top of the photograph. Color film (200 ASA) was used. After processing, the photographic prints were scanned in black and white to create a square image ( $500 \times 500$ pixels) with the edge of the scanned image defined by the limits of the full hemispheric field of view. Because of the variability in

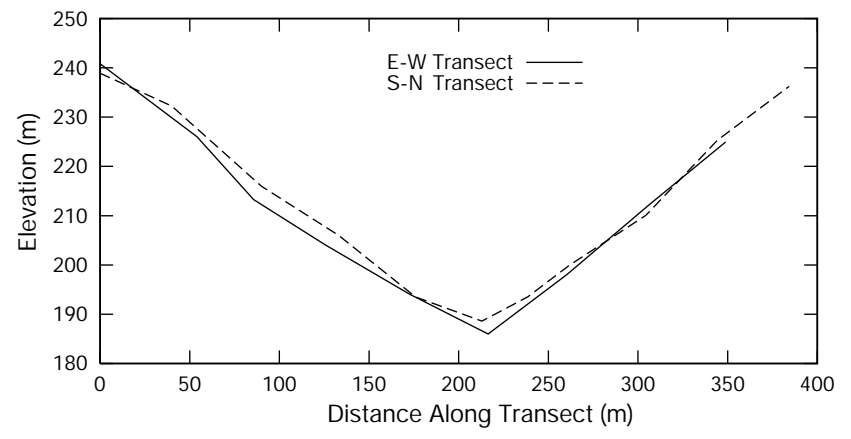

Fig. 2. Topographic profiles of the 2 ravines (E-W and S-N orientations) within HNF (located on Fig. 1). Vertical exaggeration $=2.8$ 
photographic processing and in the conditions under which the photographs were taken (for example, on occasions the foliage was very brightly lit), each image was visually inspected to ensure that the threshold detection for white (sky) and black (tree, branch, leaf) was consistent with visual interpretation. If necessary, the images were digitally retouched. The image was then analyzed using a program that calculated polar coordinates using 70 concentric rings. The black and white pixels for each ring were then summed and weighted using the method of Johnson \& Watson (1984) to determine the SVF of the site. A number of sensitivity analyses and independent evaluations were conducted, varying the procedures for scanning and subsequent analysis, for a wide range of photographs to check the consistency of results.

3.2. Cooperative climate data. To place the 1995 to 1997 field-study period in historical context, data from the Columbus, Indiana, cooperative climate station (NOAA CO-OP ID: 121747) for 1995 to 1997 are compared with 1961 to 1990 'normals' (see Robeson et al. 1998 for further discussion on the selection of this station). The Columbus station is located $36 \mathrm{~km}$ to the east of the forest site.

Overall, the historic (1961 to 1990) variability of (monthly mean) maximum air temperature for Columbus is much lower during the months of J une to August than during $\mathrm{M}$ ay. The latter shows a much larger interquartile range (Fig. 3a). Variability in minimum air temperature has a similar pattern (Fig. 3b), although the summer months have slightly more variation in minimum air temperature than in maximum air temperature.

During the 1995 to 1997 time period, 1997 appears to be the year that differs most from typical conditions. For maximum air temperature, May, J une, and August of 1997 are all well below the lower quartile of 1961 to 1990 values. Minimum air temperatures during 1997 did not exhibit the same pattern as maximum air temperature. However, precipitation was fairly high during May, June, and August of 1997, indicating that 1997 was atypically overcast, with lower daytime air temperatures, typical nighttime air temperatures, and abundant precipitation. Other years have inconsistent patterns, although all years have relatively high minimum air temperatures in J une. August 1995 has notably high minimum and maximum temperatures.

Local weather conditions strongly influence microclimate and its variability at forested sites (Oke 1987). A detailed description of synoptic conditions for the growing season of 1997, the period of most intensive study, was compiled. This information is used to interpret changes in the day-to-day evolution of belowcanopy differences in conditions. Specific details are reported below, as appropriate.
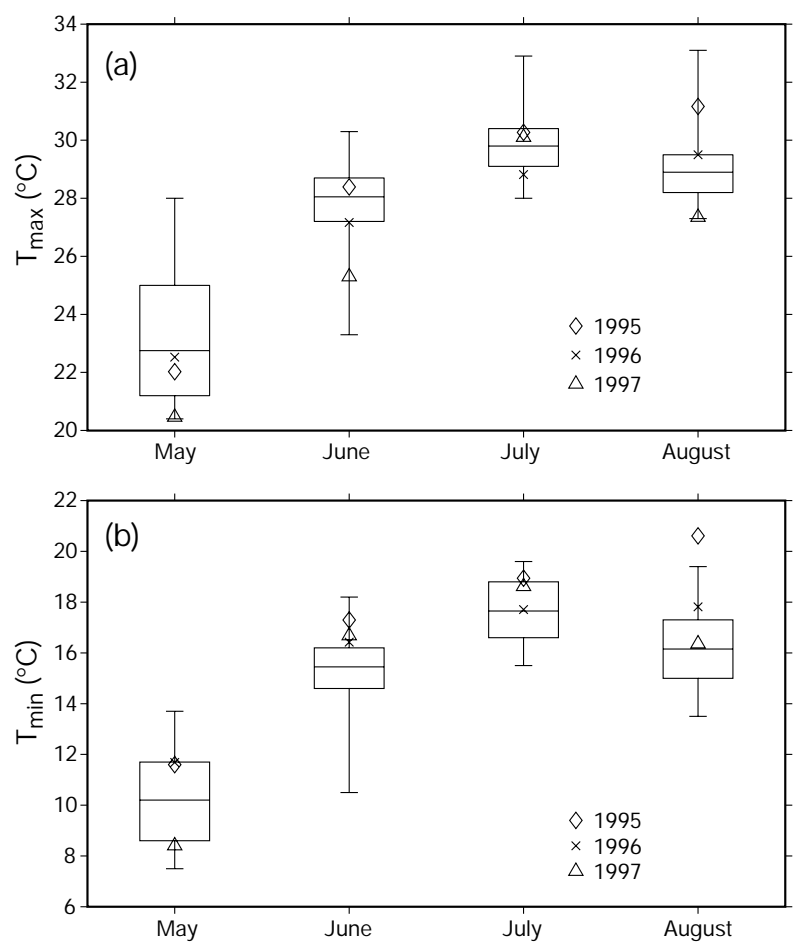

Fig. 3. Box plots of monthly averages of (a) maximum and (b) minimum air temperature for M ay to September of 1961 to 1990 at Columbus, Indiana. The minimum, lower quartile, median, upper quartile, and maximum value of the monthly data over the 1961 to 1990 period are indicated. Monthly averages for 1995 to 1997 are plotted for comparison

\section{RESULTS}

\subsection{Canopy cover}

The temporal evolution of leaf emergence and canopy closure, as measured by SVF, is fairly consistent for all years (Fig. 4). Canopy cover changes rapidly between Days 120 and 145 (late A pril through May):

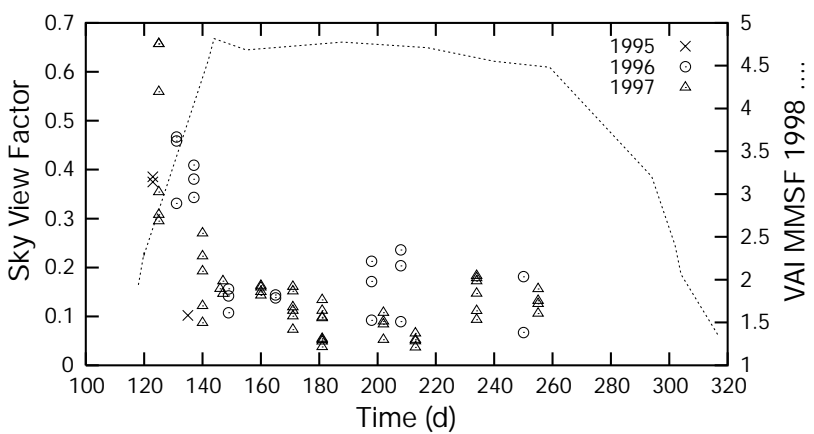

Fig. 4. Sky view factors (fraction of hemisphere that is open sky) at the fixed climate station sites in HNF during the growing seasons of 1995 to 1997. Seasonal evolution of Vegetation A rea Index (VAI) $\left(\mathrm{m}^{2} \mathrm{~m}^{-2}\right)$ for the nearby M MSF site in 1998 is superimposed (data from Schmid et al. 2000) 
SVFs fall from greater than $60 \%$ (few leaves/fairly open) to less than $20 \%$ (full canopy cover). From late May through the remainder of the summer, values drop only slightly, down to a minimum of approximately 0.1. In all years, micro-meteorological and SVF measurements ended before leaf-off.

M easurements of canopy structure, specifically Vegetation (leaf and bole) Area Index (VAI) at a nearby site, in the Morgan Monroe State Forest (MMSF) (Schmid et al. 2000), show a very similar (but inverse) temporal pattern to the SVFs documented at HNF. In 1998, VAI at MMSF reached maximum values by Day 142 (M ay 22), after which values were more or less constant through to late August/September, when the foliage began to fall. Absolute VAI values at MMSF range from $\sim 1.3$ for leaf-off (i.e., the bole area index) to -4.5 with full canopy cover. The structure and composition of the forest are very similar at both the HNF and MMSF sites; thus, VAIs are likely to be similar at HNF.

\subsection{Below-canopy spatial variability of air temperature (1997)}

\subsubsection{Trends through the growing season}

Daily maximum and minimum air temperatures recorded at each location within the 2 (E-W and S-N) ravines through the growing season of 1997 are plotted in Fig. 5. Maximum differences in the maximum and minimum temperatures on each transect (using all possible pairs of stations) also are shown.

For the S- $\mathrm{N}$ transect, differences in maximum daily temperatures between sites range from a maximum of $4.1^{\circ} \mathrm{C}$ down to $0.7^{\circ} \mathrm{C}$ (average difference of $2.2^{\circ} \mathrm{C}$ ). Differences between sites are smaller for the E-Woriented ravine (Fig. 5). There, maximum differences do not exceed $3.2^{\circ} \mathrm{C}$ and the average difference was only $1.8^{\circ} \mathrm{C}$. With respect to minimum temperatures, the largest differences again are for the $\mathrm{S}-\mathrm{N}$ ravine, ranging up to $4.5^{\circ} \mathrm{C}$ (although the average is only $1.1^{\circ} \mathrm{C}$ ). For the $\mathrm{E}-\mathrm{W}$ ravine, minimum temperature differences are smaller and always less than $3.3^{\circ} \mathrm{C}$ (average difference of $1.0^{\circ} \mathrm{C}$ ).

As expected, both minimum and maximum temperatures increase over the course of the growing season (temperatures are shown here through the end of August, Day 242). Clearly there is considerable variability on a day-to-day basis, which can be attributed to synoptic disturbances. The diurnal air temperature range (daily maximum - daily minimum) at each site increases from approximately $10^{\circ} \mathrm{C}$ (as low as $5^{\circ} \mathrm{C}$ ) before Day 140 , to $12-20^{\circ} \mathrm{C}$ for the remainder of the growing season. Differences in maximum air temperatures are greater on warmer days, and depressed on cooler, cloudy days (Fig. 5a). Once maximum air temperature exceeds $23^{\circ} \mathrm{C}$, spatial differences in temperature al ways exceed $1^{\circ} \mathrm{C}$, climbing to $\sim 3^{\circ} \mathrm{C}$ at maximum temperatures of $35^{\circ} \mathrm{C}$. Generally, spatial differences in minimum temperatures decrease as minimum temperatures increase. However, there is considerable scatter in the relationship, particularly at lower temperatures (Fig. 5b). With 1 notable exception (Day 149), variability between sites is lower early in the growing season (before Day 160), under an incomplete canopy. Maximum temperatures are more spatially variable than minimum temperatures.

\subsubsection{Space-time patterns}

Daily maximum and minimum temperatures at specific locations give only partial information about differences between sites. For many biological systems, it is not just the maximum or minimum temperature that exerts a control, rather it is the number of hours above or below a specific threshold that is important: the concept of thermal time (Sturman \& Tapper 1996). In order to illustrate the evolution and persistence of differences between sites on a day-to-day basis, subsets of data for the 2 ravines for different periods in the growing season were selected. These periods (Days 145-150 (May 25-30), Days 158-163 (J une 7-12), Days 194-198 (J uly 13-17), and Days 230-235 (August 18-23), all in 1997) were chosen to represent (1) different times in the growing season and thus conditions of canopy closure, (2) days with contrasting synoptic conditions, and (3) periods with minimal amounts of missing data. The plots (Fig. 6) show the hourly data for all the sites within each of the 2 ravines ( $\mathrm{E}-\mathrm{W}$ and $\mathrm{S}-\mathrm{N}$ transects). On the vertical axis is space (distance across the ravine), while the horizontal scale shows time (data for 30 min averages are plotted). To provide a regular spatial grid, and to fill missing data, interpolation between sites is done linearly. These plots show the time and location of the maximum and minimum temperatures and the duration above and below certain values in different areas within the ravines.

Before the canopy closes, Days 145-149, temperatures in both ravines are very similar and show consistent patterns through time (Fig. 6a). Synoptic conditions over this $5 \mathrm{~d}$ period changed from a low pressure centered over the region on Day 145, to the passage of a cold front on Day 146, lingering precipitation on Days 147 and 148, and the development of high pressure on Day 150. For all days, temperatures in both ravines are coolest, both by day and night, at the bottom of the ravine. This is more apparent in the S-N ravine, where distinct minima throughout the day occur at the bottom-most site (distance can be related to topo- 

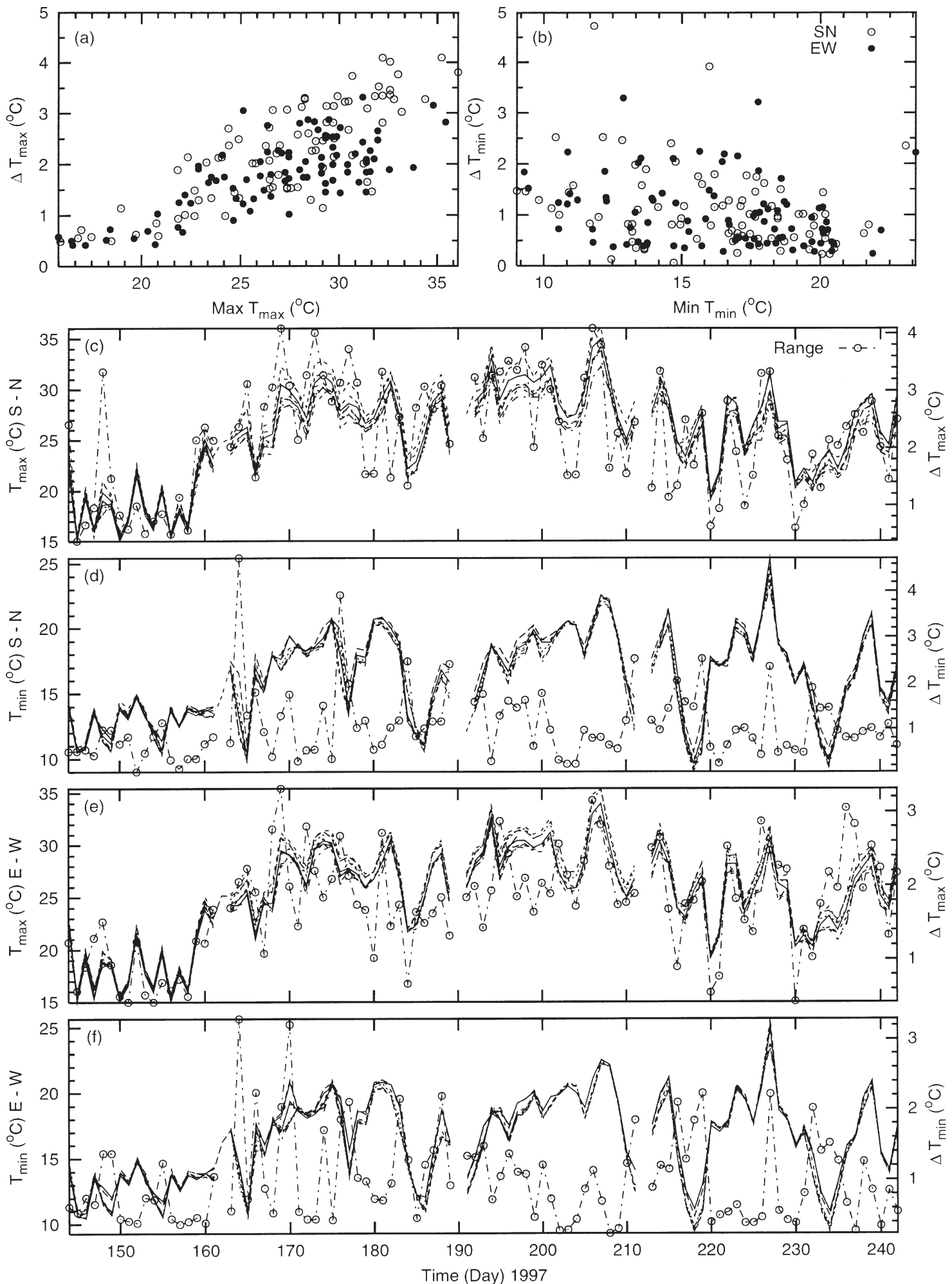

Fig. 5. Daily maximum and minimum air temperatures $\left({ }^{\circ} \mathrm{C}\right)$ from the HOBO sensors along the E-W and S-N transects (summer 1997): (a) daily values of maximum difference in maximum air temperature (i.e., the temperature of the warmest sensor minus the temperature of the coldest sensor, $\Delta \mathrm{T}$ ) plotted against the maximum temperature for the transect (for Days 150 to 242 ); (b) as for (a) but for minimum temperatures (for Days 150 to 242); (c) daily maximum and (d) daily minimum temperatures for each of the stations on the S-N transect (lines without symbols, left $\mathrm{y}$-axis), with the maximum difference (range) between the stations (dashed line with symbols, right y-axis); (e) and (f) as for (c) and (d), but for the E-W transect 

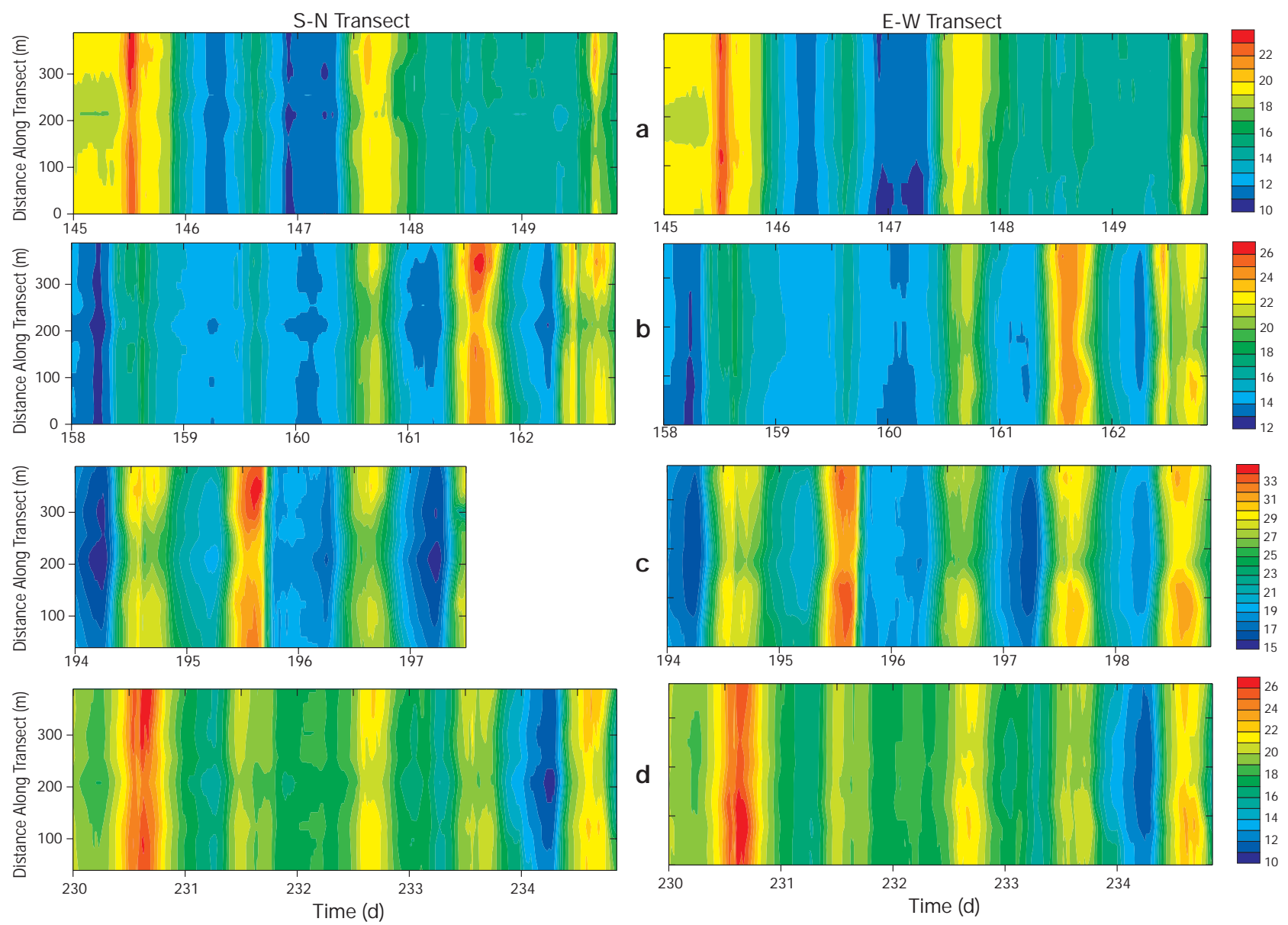

Fig. 6. Spatial patterns of air temperatures $\left({ }^{\circ} \mathrm{C}\right)$ measured by HOBO sensors in the S-N and E-W ravines during 1997 for Days: (a) 145-149, (b) 158-162, (c) 194-197, and (d) 230-234, inclusive. Horizontal axis is time; vertical axis is distance along transect

graphic position on Fig. 2). Daily temperatures increase more, and are more similar across all sites in the $\mathrm{E}-\mathrm{W}$ ravine. The north-facing slope in the $\mathrm{S}-\mathrm{N}$ ravine often is $1^{\circ} \mathrm{C}$, or more, cooler than the opposite southfacing slope. In the $\mathrm{E}-\mathrm{W}$ ravine, temperatures are slightly cooler on the west-facing slope, notably in the morning.

The next sequence of days, Days 158-162, illustrate spatial variability of temperatures under a recently closed canopy (Fig. 6b). Over this period, synoptic conditions change from a low-pressure system passing over the area to dominance by a high-pressure system. As with the earlier sequence of days, differences between sites are more evident under the anticyclonic, clear sky conditions. On the first 2 days, Days 158 and 159 , differences within the ravines are minimal. Overall the $\mathrm{E}-\mathrm{W}$ ravine is slightly warmer. For Days 160 to 162, maximum temperatures are lower at the base of the ravine, most notably in the S-N ravine. In the $\mathrm{E}-\mathrm{W}$ ravine, temperatures and their diurnal pattern are much more consistent; however, on Day 162 the bot- tom $50 \mathrm{~m}$ of the ravine does remain cooler. Air temperatures, as expected, are greater on the south facing slopes in the mid to late afternoon $\left(2^{\circ} \mathrm{C}\right.$, or more, warmer than elsewhere), and change more rapidly through time at these locations than at any of the other sites.

Of the 4 time periods shown, spatial variability is most evident between Days 194 and 197 (data for the S-N transect is truncated because of instrumentation problems at one of the sites). This is a period dominated synoptically by a high-pressure system. Again, temperatures are coolest at the base of the $\mathrm{S}-\mathrm{N}$ ravine, both by day and night. Temperatures are warmest on the south-facing slope (Fig. 6c). Differences between sites in the E-W ravine again are much smaller than in the $\mathrm{S}-\mathrm{N}$ ravine. The timing of the maxima and minima is similar in both ravines and for most sites within them.

For the period between Days 230 and 234, synoptic conditions changed from anticyclonic, to the influence of an upper-level trough, to the re-establishment of 
anticyclonic conditions. For this period temperatures are slightly warmer in the E-W ravine (Fig. 6d). Again the bottom of the $\mathrm{S}-\mathrm{N}$ ravine is coolest, by $\sim 2^{\circ} \mathrm{C}$ in the early afternoon, and temperatures remain cooler for longer at night.

In summary, air temperatures within the ravines show a consistent pattern over the course of the growing season. Air temperatures are consistently (1) cooler and (2) cooler for longer at the base of the $\mathrm{S}-\mathrm{N}$ ravine, by $2^{\circ} \mathrm{C}$. Temperatures are warmest on the south-facing slope of the $\mathrm{S}-\mathrm{N}$ ravine, and much more consistent across the $\mathrm{E}-\mathrm{W}$ ravine. Differences are more pronounced under clear skies and anticyclonic conditions, and more pronounced later in the growing season. Differences temporally, hour to hour and day to day, are much greater than they are spatially.

\subsection{Variability between years: 'fixed' stations (1995 to 1997)}

In order to place the results from 1997 in context, data were collected at a more restricted number of sites (east, west and bottom of the E-W ravine; locations shown in Fig. 1) for 3 growing seasons (1995 to 1997). Short and net all-wave radiation, precipitation, relative humidity, wind speed, soil heat flux, soil moisture and temperature were all measured, in addition to air temperature. Selected results, which show interesting contrasts between sites, are summarized graphically in Figs. 7 to 10. It is important to note that these figures are different to Fig. 6 . Each site is plotted separately and the temporal evolution of conditions over the growing season is shown (the vertical scale is now hour of the day, the horizontal scale the day of the year).

\subsubsection{Air temperature}

Overall, the patterns in temperature documented by the fixed sites for the 3 years, confirm the spatial patterns shown by the HOBO sensors in 1997 (Fig. 7). Now, however, the day-to-day variability for the full growing season, as well as the differences between years, is evident. As expected from the NOAA cooperative climate data, conditions in August of 1995 were warmer than for any other period; conditions in May of 1997 were cooler (see Section 3.2). As documented from the HOBO sensors, these data also show cooler temperatures in the bottom of the ravine compared to the east-facing or west-facing slopes, particularly at night and in the morning. M ore notable is the fact that temperatures
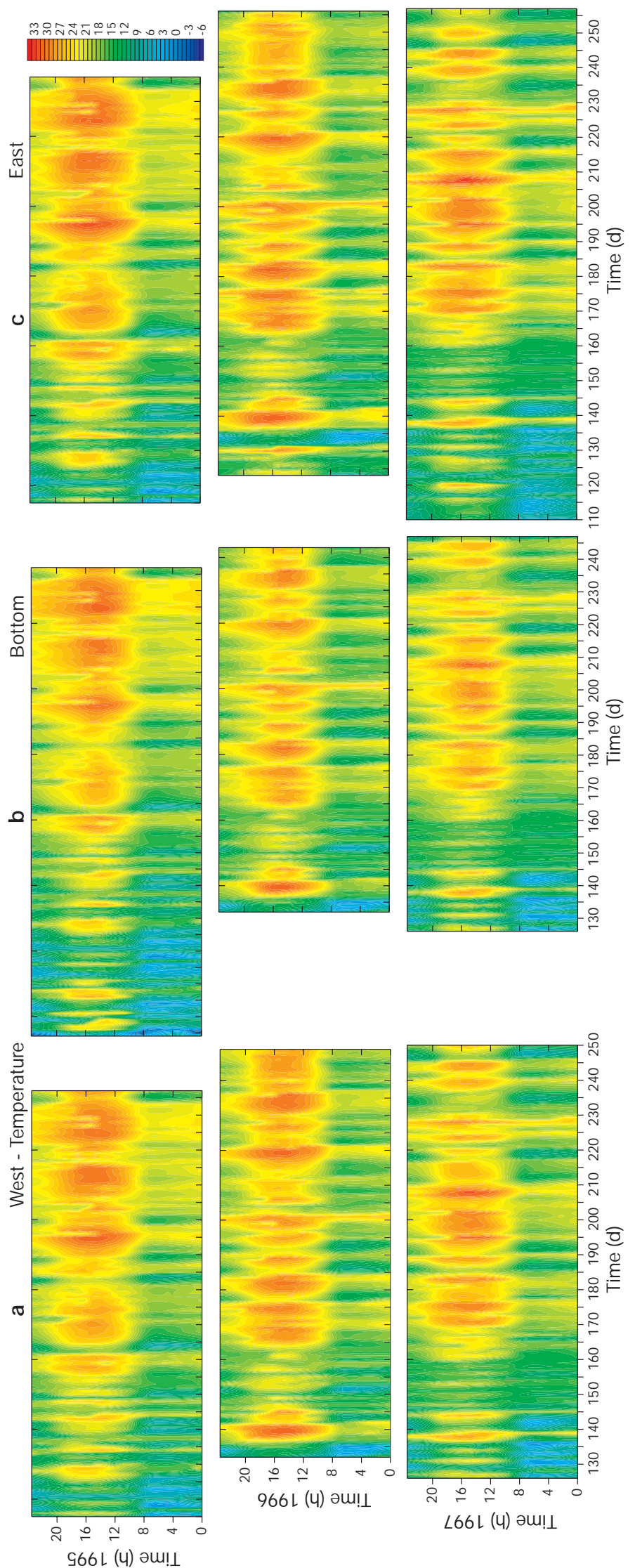
rise later in the morning and drop earlier in the evening at the bottom of the ravine. Thus there is a significantly shorter period of warm $\left(30^{\circ} \mathrm{C}\right.$ plus) temperatures (by 2 or more hours) at this site. Temperatures on the west-facing slope remain warmer later in the evening; on the east-facing slope, values increase earlier in the day. For all years, the time of the maximum and minimum air temperatures at each of the sites remains remarkably constant. The time of the maximum is earliest on the west-facing slope and bottom of the ravine (both $\sim 13: 00$ to $15: 00 \mathrm{~h}$ ), and later for the east-facing slope ( 14:00 to 16:00 h). Minimum temperatures persist until 08:00 h, slightly later at the west-facing site. Air temperatures in the early morning change rapidly.

\subsubsection{Radiation}

The temporal and spatial patterns of incoming solar and net all-wave radiation are very similar, thus only the former is presented here (Fig. 8). Seasonal variation in the radiation climate of forests is the integrated effect of changes in forest phenology, angle of incidence of the solar beam, and weather conditions affecting atmospheric transparency. At the HNF over the full growing season, forest phenology is the dominant control. Canopy closure (by Day 145) significantly reduces radiation receipt within the canopy (Fig. 8) (this is most notable in 1997). Prior to Day 145, daily maxima of up to $550 \mathrm{~W} \mathrm{~m}^{-2}$ were measured at the forest floor (1.5 m). After Day 145, maximum values drop by a factor of 3 or more. For the rest of the growing season, solar radiation does not exceed $150 \mathrm{~W} \mathrm{~m}^{-2}$, and for most of the time is below $75 \mathrm{~W} \mathrm{~m}^{-2}$. Even more notable is the fact that once the canopy closes, the length of time when solar radiation exceeds $\sim 50 \mathrm{~W} \mathrm{~m}^{-2}$ below the canopy, drops from $10 \mathrm{~h}$ or more (before Day 145) to 2 or $3 \mathrm{~h}$ maximum (after Day 145).

Solar radiation receipt is greatest on the west-facing slope in the mid to late afternoon. It is least, both in magnitude and duration, at the bottom of the ravine. By the second part of the growing season, at the base of the ravine the number of hours when incoming solar radiation $\left(>5 \mathrm{~W} \mathrm{~m}^{-2}\right.$ ) is received is much shorter (4 plus hours) than on the east or west slopes. This is consistent with the pattern observed in temperature at the base of the ravine: a later and earlier rise and fall, respectively. The interaction of solar geometry and the forest canopy is evident at the west-facing site. Two solar radiation maxima are evident on most days: one close to solar noon, the other later $(\sim 16: 00 \mathrm{~h})$ in the afternoon. Although there is obvious day-to-day variability, patterns at each of the sites between years are remarkably similar.
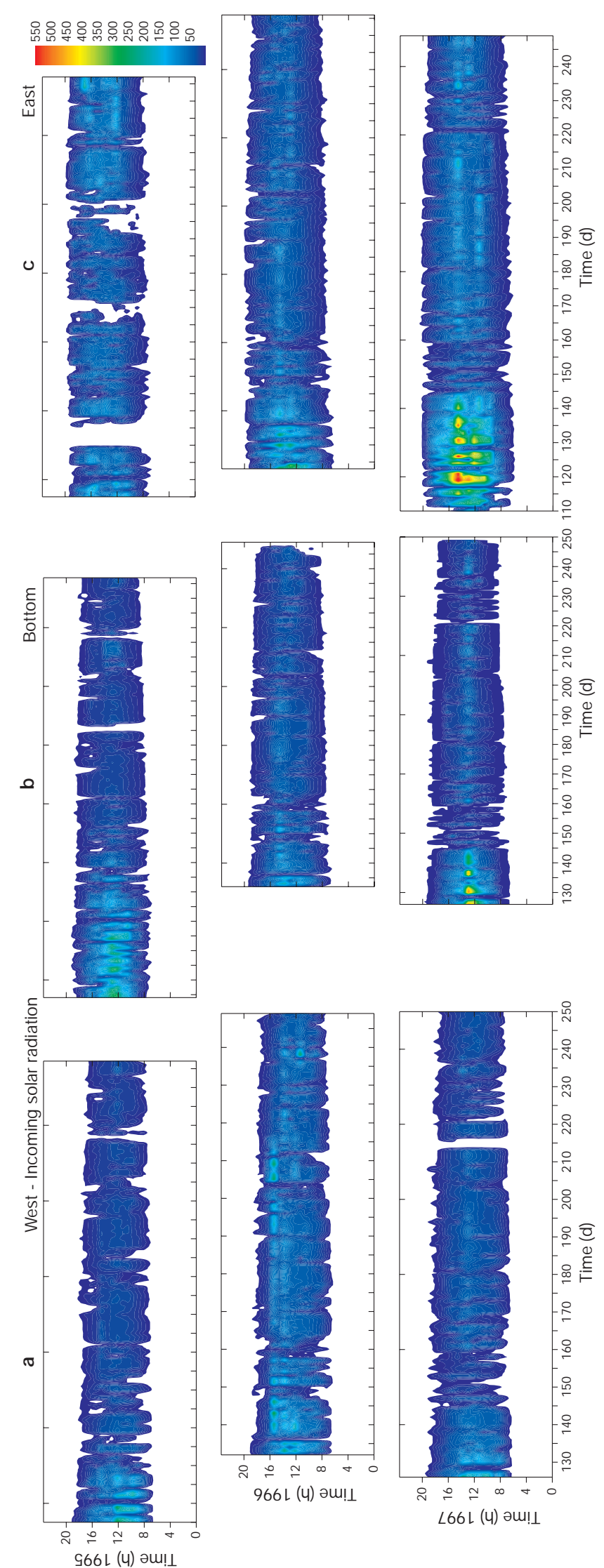

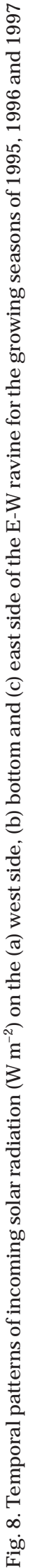


Previous studies of forest interiors (Chen et al. 1993, Chen \& Franklin 1997) have documented significant variability in solar radiation under forest canopies (from zero to full sunlight). Most forests have natural gaps, which allow radiation to penetrate locally below the canopy. Here no such gaps were sampled, and given the fairly consistent canopy cover, only limited variation between sites is evident. However, it is important to caution that measurements presented here are for only 3 sites.

\subsubsection{Humidity}

In this study, the dominant control on below-canopy variability in humidity is canopy cover. Before Day 145 , when full canopy cover effectively is established, on most days humidity within the forest falls to less than $20 \%$, and on occasions does not reach $100 \%$ at night. However, after Day 145, humidity drops appreciably below $100 \%$ only between $08: 00$ and $20: 00 \mathrm{~h}$, in response to the greatest temperatures (contrast Figs. 7 $\&$ 9). On most afternoons, humidity drops below $70 \%$ only for 4 or $5 \mathrm{~h}$; although occasional values drop below $50 \%$. Generally, the west-facing slope has lower humidity values than does the bottom of the ravine or the east-facing slope, and relative humidities on the west-facing slope remain lower in the evening for longer. This is particularly evident in 1997. Notable exceptions, however, occur during Days 180 to 190 in 1996 at the bottom of the ravine. Overall, the bottom of the ravine is more humid than either of the 2 slopes.

Even though temperatures were much warmer in the latter part of 1995 (Section 4.3.1), relative humidity was actually greater during this time. This is consistent with the rainfall measured at the site; 1996 and 1997 both were relatively dry in August, 1995 was much wetter. Soil moisture (not shown) is much greater at the bottom of the ravine, and lowest on the east-facing slope. Values drop fairly systematically (from $\sim 50$ to $20 \%$ by mass) at all sites in all years through the growing season.

\subsubsection{Wind}

Wind speed below the canopy is strongly affected by the presence of leaves. Values at all sites drop significantly once the canopy closes (Fig. 10). After Day 145, in all years and at all sites, wind speeds (at height $1.5 \mathrm{~m}$ ) do not exceed $1 \mathrm{~m} \mathrm{~s}^{-1}$ for $30 \mathrm{~min}$ averages. Before Day 145, 30 min wind speed averages ranged up to $3.8 \mathrm{~m} \mathrm{~s}^{-1}$. Regardless of canopy cover, wind speeds are greatest in the early mid afternoon and almost non-detectable at night. Increasingly through the growing season, measurable winds only occur dur-
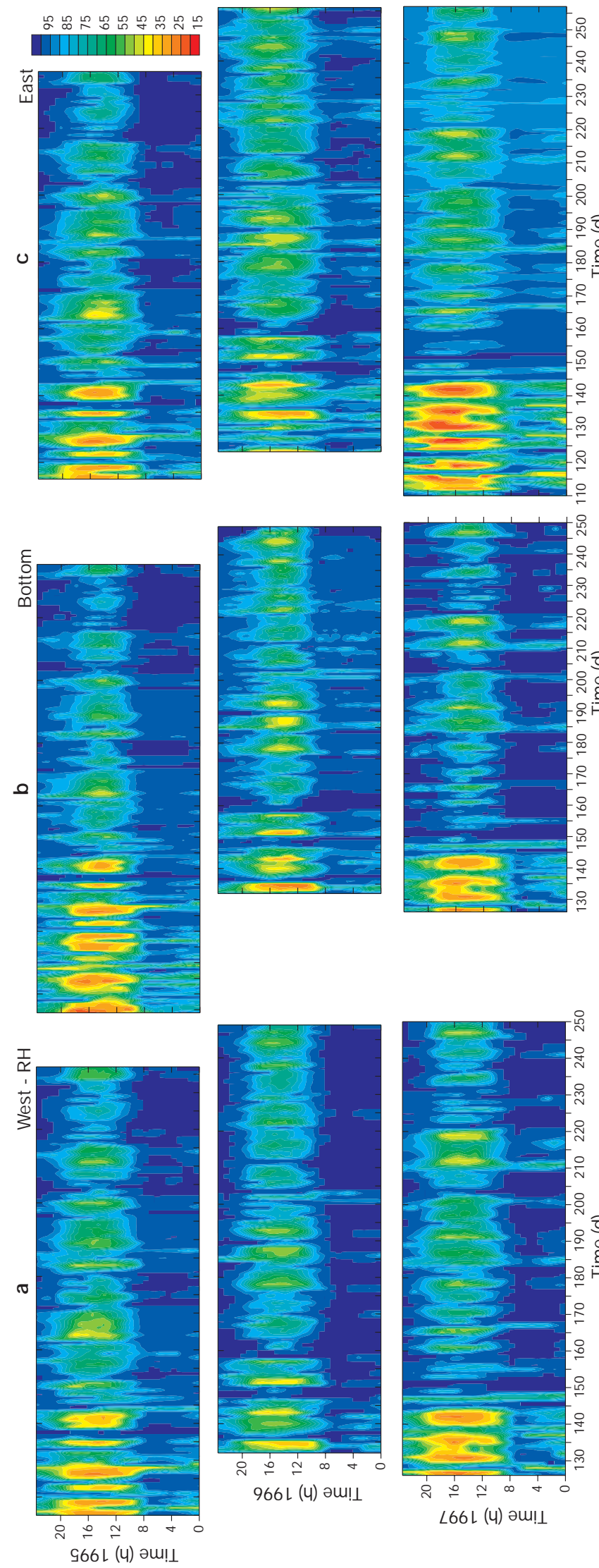
ing the warmest part of the day. In general, 1995 was windier than the other years.

Wind speeds below the canopy are greatest at the bottom of the ravine (though this is not the case in 1997) and the east-facing slope (where they remain measurable for longer each day) (Fig. 10). Our anemometers, with thresholds of $0.2 \mathrm{~m} \mathrm{~s}^{-1}$, did not document cold air drainage at night in the base of the ravine once the canopy was in-leaf. It is probable that such winds did occur but were not measured. Nocturnal drainage at forested sites is the focus of intensive study (Lee 1998, Finnigan 1999).

\section{IM PLIC ATIO N S}

The approach adopted in this study is empirical: the aim is to document the magnitude and spatial variability of below-canopy micro-climatic conditions. It is important to emphasize that the study area is a secondary growth forest with a closed canopy, approximately 80 to $100 \mathrm{yr}$ old (with a few older embedded trees). Old growth forests typically are characterized by greater canopy heterogeneity and gap formation. The data presented should be of direct interest to ecologists and biogeochemists modeling climate-dependent processes within midlatitude deciduous forests with similar histories. The values presented here can be used to simulate both mean conditions and variability in space and time. Clearly, the significance of the differences documented depends on the ecological and/or biogeochemical process of interest. Here we discuss a small number of applications and consider the significance of our results.

In the 3 years of measurements, at the locations instrumented in this study, maximum air temperatures within the forest never exceeded $34^{\circ} \mathrm{C}$, and after the canopy was in place (Day 145), minimum air temperatures did not drop below $8^{\circ} \mathrm{C}$ (virtually always above $10^{\circ} \mathrm{C}$ ) (until Day 250). At a nearby cooperative climate station over the same period, maximum air temperatures ranged up to $36^{\circ} \mathrm{C}$. Thus the forest canopy clearly reduces heat stress and the chance of heat damage to ground flora. This result is consistent with earlier work (see, for example, Lee 1978).

The maximum differences in air temperature documented within the forest $\left(4.5^{\circ} \mathrm{C}\right)$ are similar in magnitude to those documented in previous studies between open and forested sites (see, for example, Morecroft et al. 1998). On average, differences are smaller (of the order of $2^{\circ} \mathrm{C}$ ), and differences are larger for maximum than minimum air temperatures. This variability highlights the problem of extrapolating from 1 reference site to all locations
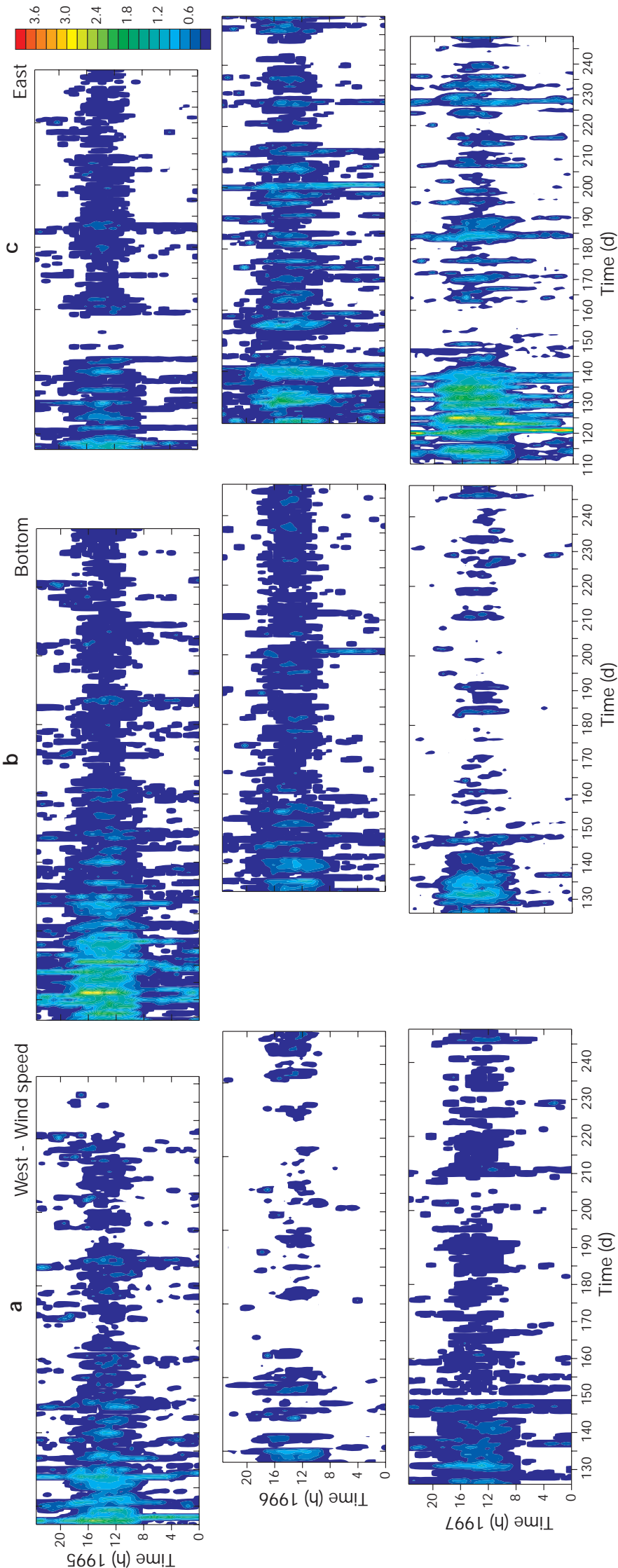
within the forest; conditions within the forest are variable. Obviously, topography exerts a major control at HNF (both aspect and position on the slope). Although not characteristic of all forested sites, the rolling topography that underlies the HNF (Fig. 1) is common for many large forests in the heavily managed landscape of the agricultural Midwest. In this and other regions, forests tend to occupy those areas topographically too dissected to be farmed commercially. Thus the differences documented here have broad relevance.

The differences through the growing season, day to day, are even more significant than the spatial differences within the forest. This is particularly evident in the case of air temperature. Synoptic conditions exert a significant control and should be considered in any study of inter-annual variability and/or when evaluating the potential impacts in global warming.

Heat and moisture, in both air and soil, exert important controls on the rates of litter decomposition and soil respiration rates, processes important in both ecological and carbon sequestration studies. Studies by Greco \& Baldocchi (1996) for an oak-hickory forest in Tennessee and by Valentini et al. (1996) for a beech forest in central Italy document increases in soil respiration, by factors of 1.62 and 2.17 , respectively, with an increase in air temperature of $10^{\circ} \mathrm{C}$. Measurable differences in decomposition and soil respiration rates would thus be expected with topography/aspect in many mid-latitude deciduous forests. Rates would be expected to be lower at the base of the ravine and greater on south-facing slopes (by a factor of $1.3-1.6$ ). At a proximal study Castellanos et al. (1999) document differences in soil carbon pools: NE-facing stands have more carbon than SW-facing ones, consistent with the air temperature results of this study. Thus, in measurement and modeling studies of such processes, the absolute temperatures and their variability, both in space and time, must be included in sampling design and/or model simulations.

One of the original goals of this study was to investigate the effects of micro-climatic conditions on the productivity of neo-tropical birds. Climate exerts both direct and indirect effects. With a resting core temperature of 40 to $41^{\circ} \mathrm{C}$ ( 3 to $5^{\circ} \mathrm{C}$ warmer than mammals), birds are the highest temperature endothermic vertebrates (Wiersma \& Piersma 1994). Their environment is usually cooler than their bodies and the insulation provided by plumage is fairly small. Clearly, reduced temperatures below the canopy documented in this study will enhance heat loss, although this will be offset largely by the effects of reduced wind speed. In terms of other direct effects, nest humidity represents the micro-climatic factor of primary importance in determining egg dehydration; specific effects depend on the species of bird, variations in egg porosity, and exact location of eggs within a nest (Walsberg 1980). The more humid sites in the HNF are at the bottom of the $\mathrm{E}-\mathrm{W}$ ravine, which is where most nest sites were actually found. Indirect effects, such as the influences of climate on food and nest-site availability, also are important, but even more complex than direct effects. The relation between micro-scale climatic conditions in the HNF and nesting patterns and success are the subject of ongoing investigation.

In terms of spatial variability in micro-climatic conditions it is important to caution that we have documented only horizontal differences at 1 height (near the forest floor), vertical changes within the forest, higher in the understory and throughout the canopy, are not documented.

\section{SUMMARY AND CONCLUSIONS}

Spatial and temporal differences in microclimatic conditions under a mid-latitude deciduous forest canopy are documented for 3 growing seasons, 1995 to 1997, inclusive. For all sites and in all years, conditions change markedly at the start of the growing season (Days 120 to 145), coincident with onset of leaf-out and the development of full canopy cover. With leaf-on, radiation and wind speed are significantly reduced below the canopy, both in magnitude and duration, while relative humidity is increased.

Within the ravines, the maximum differences in daily maximum air temperature (i.e., the greatest contrast in maximum air temperature between any 2 recording sites in 1 ravine) range from 0.5 to $4.1^{\circ} \mathrm{C}$, and from 0 to $4.5^{\circ} \mathrm{C}$ for minimum temperatures. Average differences are smaller: $\sim 2^{\circ} \mathrm{C}$ for daily maximum temperatures, $\sim 1^{\circ} \mathrm{C}$ for daily minimum temperatures. In all years of measurements, 1995 to 1997, maximum temperatures never exceeded $34^{\circ} \mathrm{C}$, and after the canopy was in place (Day 145), minimum temperatures never dropped below $8^{\circ} \mathrm{C}$ (measurements continued until Day 250). At a more limited number of sites, differences within the forest in solar radiation of $100 \mathrm{~W} \mathrm{~m}^{-2}$, relative humidity (10 to $15 \%$ on minimum values), and wind speed $\left(0.5 \mathrm{~m} \mathrm{~s}^{-1}\right)$ were observed. $M$ easurements were not made in forest gaps nor near forest edges. Local weather conditions have a strong influence on the spatial and temporal variability of all the micro-climatic variables considered. In general, differences within the forest are greater on clear, sunny days. Once the canopy closes, the effects of topography and associated aspect/geometry dominate over micro-scale differences due to canopy structure. Less radiation, lower temperatures, higher relative humidity and higher wind speeds all are documented at the bottom of the ravines. 
The differences in micro-climatic conditions documented within the forest are of the same order as results from previous studies contrasting open and forest sites. In many studies of ecological and biogeochemical processes in forests, therefore, within-forest climatic conditions cannot be assumed to be homogeneous or identical to those at nearby open sites.

Acknowledgements. We would like to thank all those who helped with data collection and processing: Mark Hubble, Michael J anis, Thomas King, Mark McKee, Jason Moore, Brian Offerle, Melanie Roy, Catherine Souch, Jane Southworth, and Meg Swindal. Don Whitehead (Department of Biology, Indiana University) and students also provided a great deal of assistance in the field. In addition, we thank the US Department of Agriculture Forest Service for permission to conduct fieldwork in Hoosier $\mathrm{N}$ ational Forest. This research was funded by the National Institute for Global Environmental Change through the US Department of Energy (DOE; Cooperative Agreement No. DE-FC03-90ER61010). Any opinions, findings, and conclusions or recommendations expressed in this publication are those of the authors and do not necessarily reflect the views of the DOE.

\section{LITERATURE CITED}

Braun EL (1972) Deciduous forests of Eastern North America. Hafner Press, New York

Castellanos EJ , J ohnston J J , Ehman J L, Slusher RB, Randolph JC (1999) Above- and below-ground carbon storage in secondary temperate deciduous forests. 84th Annual M eeting of the Ecological Society of America, Spokane, WA

Chen J , Franklin J F (1997) Growing season microclimate variability within an old-growth Douglas-fir forest. Clim Res 8: 21-34

Chen J, Franklin J F, Spies TA (1993) Contrasting microclimates among clearcut, edge and interior old growth Douglas-fir forest. Agric For M eteorol 63:219-237

Finnigan J (1999) A comment on the paper by Lee (1998): On micrometeorological observations of surface-air exchange over tall vegetation. Agric For M eteorol 97:55-64

Geiger R (1965) The climate near the ground. Harvard University Press, Cambridge, MA

Greco S, Baldocchi DD (1996) Seasonal variations of $\mathrm{CO}_{2}$ and water vapor exchange rates over a temperate deciduous forest. Global Change Biol 2:183-198

Editorial responsibility: Laurence Kalkstein, Newark, Delaware, USA
J ohnson GT, Watson ID (1984) The determination of sky view-factors in urban canyons. J Clim Appl Meteorol 23: 329-335

Lee R (1978) Forest micrometeorology. Columbia University Press, New York

Lee X (1998) On micrometeorological observations of surfaceair exchange over tall vegetation. Agric For M eteorol 91: 39-49

Loveland TR, Merchant J W, Brown J F, Ohlen DO, Reed BC, Olson P, Hutchinson J (1995) Seasonal land-cover regions of the United States. Ann Assoc Am Geogr 85:339-355

McCaughey J H, A miro BD, Robertson AW, Spittlehouse DL (1997) Forest environments. In: Bailey WG, Oke TR, Rouse WR (eds) The surface climates of Canada. M cGill Queen's University Press, M ontreal, p 247-276

Morecroft MD, Taylor ME, Oliver HR (1998) Air and soil microclimates of deciduous woodland compared with an open site. Agric For M eteorol 90:141-156

Oke TR (1987) Boundary layer climates. M ethuen, London

Robeson SM, Grimmond CSB, Schoof J (1998) Comparison of open site and below-canopy climatic conditions within an eastern North American deciduous forest. Preprints of the 23rd Conference on Agricultural and Forest Meteorology, Albuquerque, NM, November. American Meteorological Society, Boston MA, p 184-187

Robinson SK, Thompson FR, Donovan T, Whitehead DR, Faaborg J (1995) Regional forest fragmentation and the resting success of migratory birds. Science 267:1987-1990

Rodenhouse NL (1992) Potential effects of climatic change on Neotropical Migrant Landbird. Conserv Biol 6:263-272

Root TL, Schneider SH (1993) Can large scale climatic models be linked with multi-scale ecological simulations. Conserv Biol 7:256-270

Schmid HP, Grimmond CSB, Cropley FD, Offerle B, Su HB (2000) Measurements of $\mathrm{CO}_{2}$ and energy fluxes over a mixed hardwood forest in the Midwestern United States. Agric For M eteorol 103:355-373

Sturman A, Tapper N (1996) The weather and climate of Australia and New Zealand. Oxford University Press, Melbourne

Valentini R, de Angelis P, Matteuci G, Monaco R, Dore S, Scarascia Mugnozza GE (1996) Seasonal net carbon dioxide exchange of a beech forest with the atmosphere. Global Change Biol 2:199-207

Walsberg GE (1980) The gaseous microclimate of the avian nest during incubation. Am Zool 20:363-372

Wiersma P, Piersma T (1994) Effects of microhabitat flocking, climate and migratory goal on the energy expenditure in the annual cycle of red knots. The Condor 96:257-279

Winnett SM (1998) Potential effects of climate change on U.S. forests: a review. Clim Res 11:39-49

Submitted: August 12, 1999; Accepted: December 21, 1999 Proofs received from author(s): M ay 15, 2000 